\title{
MACROCYTIC ANAEMIA IN CHILDREN WITH A REPORT OF THREE CASES SHOWING MEGALOBLASTIC ERYTHROPOIESIS
}

\author{
BY \\ L. J. DAVIS, M.D., F.R.C P.E., M.R.C.P. \\ (From the Department of Medicine, University of Edinburgh)
}

\section{General considerations}

Anaemias characterized by a macrocytic peripheral blood picture may be divided on the basis of sternal puncture findings into two main groups according to whether the marrow picture is megaloblastic or normoblastic. A megaloblastic marrow picture, which is seen in its typical form in relapsed cases of Addisonian pernicious anaemia, may be recognized by the following features (see fig. 1):-

A high proportion of the red cell precursors are large cells with abundant dark-blue cytoplasm and large finely reticulated nuclei in which nucleolar remnants may or may not be present. The nomenclature of these cells continues to arouse considerable controversy, and various names have been given to cell types differentiated from each other by finer points of cytological detail. However, I prefer to designate these cells by the generic name of early erythroblast and support the view that their diagnostic significance lies in their quantity rather than their quality. According to this view the presence in marrow films of occasional cells belonging to the series is of no diagnostic significance since they may occur in small numbers in health and in many types of anaemia, but their presence in relatively large numbers is characteristic of megaloblastic anaemias.

Cells qualitatively diagnostic of megaloblastic erythropoiesis are seen among the more mature red cell precursors showing varying degrees of haemoglobination. Such cells may be identified as megaloblasts by their size and particularly by the loosely woven character of the nuclear chromatin. Normoblasts at equivalent stages of haemoglobination are smaller and have nuclei which are much more dense and lumpy in structure.

In severe untreated megaloblastic anaemias the marrow picture is so characteristic that it is recognizable at a glance. It must be admitted, however, that in mild cases, especially if an iron deficiency is also present, and in cases in which liver therapy has recently been instituted, the diagnosis may not be easy and may necessitate careful study. Indeed, effective liver therapy may result in such a rapid modification of the marrow picture that evidence of megaloblastic erythropoiesis may disappear within a few days of the start of treatment.

A megaloblastic marrow picture is aiways associated with defective erythropoiesis, the erythrocytes being defective both in quantity and quality, and the presence of numerous macrocytes in the peripheral blood is usually a conspicuous feature.

It should be noted, however, that while the peripheral blood picture is usually hyperchromic, it may occasionally be hypochromic in cases in which a severe iron deficiency is also operating. Trowell (1943) has drawn attention to the relatively frequent occurrence of such 'dimorphic anaemias' in the tropics; and in Edinburgh this feature has been noted in megaloblastic anaemias of pregnancy. Accordingly it will be seen that a high colour index is not necessarily an accompaniment of macrocytosis, although, in temperate climates at least, it usually is so.

Megaloblastic erythropoiesis is generally considered to result from arrested maturation consequent upon lack of the anti-anaemic, or haematopoietic, principle of Castle. This deficiency most commonly results from defective formation of intrinsic factor as in Addisonian pernicious anaemia. It may also be caused by an inadequate intake of extrinsic factor as in nutritional macrocytic anaemias. Less frequently it may occur in alimentary disorders such as steatorrhoea, sprue, and coeliac disease, which may cause impaired absorption of the haematopoietic principle. Finally, megaloblastic anaemia may occasionally result from diseases of the liver since this organ is the site of storage of the haematopoietic principle, and possibly of its final elaboration (Davidson and Fullerton, 1938).

It is widely recognized that treatment by injections of fractionated liver extracts containing the haematopoietic principle is usually followed by the rapid replacement of the megaloblastic marrow picture by a normoblastic one and subsequent restoration of a normal blood picture.

Occasional cases of megaloblastic anaemia are met with, however, which are permanently or temporarily refractory to treatment with liver extracts. Thus cases of so-called ' achrestic anaemia' described by Israëls and Wilkinson (1940) were found to be partly or completely refractory to treatment. Davidson, Davis and Innes $(1942,1943)$ have described refractory cases which responded only to prolonged and intensive parenteral liver therapy. Evidence has been presented by Fullerton (1943), and by Davis and Davidson (1944) in support of the view that in certain cases of megaloblastic anaemia restoration of normal erythropoiesis is dependant upon some factor present in whole liver preparations additional to the haematopoietic principle present in fractionated liver extracts. 
Macrocytic anaemias associated with normoblastic bone-marrows are occasionally encountered in certain haemolytic syndromes, hypothyroidism, leukaemias, leuco-erythroblastosis and certain types of refractory anaemia. The macrocytic blood picture in some cases in this group is due to large numbers of reticulocytes being present, resulting in a so-called 'pseudo-macrocytosis.' In other cases, however, a true macrocytosis may occur, the mode of production of which is quite obscure.

Since macrocytic anaemias belonging to this group do not ordinarily respond to parenteral liver therapy, the demonstration of such a response in a macrocytic anaemia may be interpreted as presumptive evidence of the anaemia in question being megaloblastic in nature.

Such evidence provided by response to treatment is therefore of importance for the purposes of reviewing published descriptions of anaemic states, since descriptions of sternal marrow biopsies have only recently become commonplace, the majority of published haematological reports are confined to descriptions of the peripheral blood.

In the earlier literature particularly, many cases of macrocytic anaemia have been described as pernicious anaemia on inadequate evidence. For the acceptance of this diagnosis it is desirable that in addition to the characteristic peripheral blood picture, there should be evidence of a histamine-fast achlorhydria, of a prompt response to parenteral liver therapy, and of the absence of possible operating causes, such as tumours or steatorrhoea.

\section{Macrocytic anaemia in childhood}

In childhood macrocytic anaemias have been reported relatively infrequently.

The rarity of pernicious anaemia in the first two decades of life is exemplified by surveys published by the following authors:-Carr (1920); Panton et al. (1923); Wilson and Evans (1924); Montgomery (1926); Davidson and Gulland (1930) and Murphy (1939). Of a total of 1532 cases of pernicious anaemia only four were below the age of twenty years.

A number of individual cases of macrocytic or hyperchromic anaemia during childhood have been reported, but most of these were in infants. Bachman (1936) gave a detailed account of a case of macrocytic anaemia which responded to liver extract in a nine-month-old infant and reviewed previously published reports of ten cases of hyperchromic or pernicious anaemia in infancy. This author considers that all anaemias below the age of one year may be assumed to be nutritional in origin consequent upon such influences as dietary deficiency, defective absorption, vomiting and diarrhoea, or defective storage due to hepatic dysfunction.

Parsons and Hawksley (1933) describe three cases, not referred to by Bachman, of mild hyperchromic anaemia associated with coeliac disease in very young children.

Since Bachman's paper seven further cases in infants have been reported by Langmead and
Doniach (1937); Mödlinger (1937); Veeneklass (1940); Cole (1941) and Fouts and Garber (1942). In only one of these, a thirteen-month-old infant, was a histamine-fast achlorhydria recorded. In three of the cases the anaemia was attributed to a diet of goat's milk.

In view of the lability of the haematopoietic system in infancy, the interpretation of haematological findings obviously calls for extreme caution. Accordingly, in infants a diagnosis of pernicious anaemia is justifiable only after rigid criteria have been satisfied. It is doubtful if in any of the published cases have these requirements been fulfilled. In children above the age of infancy, anaemias claimed to be macrocytic in type or to display other resemblances to pernicious anaemia have seldom been reported.

I have succeeded in tracing reports of only sixteen cases, which are published by the following authors. The age of each patient in years is indicated after the relevant reference. Kusonoki (1914) -6; Vischer (1923) two cases-3 and 4; Fanconi (1927) three brothers-4, 5 and 7; Castle (1928)-13; Faber (1928) - 4; Eckman and Rowe (1929)_11; Kersley (1935)_-11; Adams and McQuarrie (1938)—12; Murphy (1939)—12; Barbé

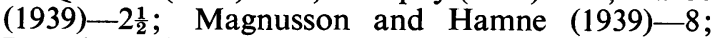
Templeton (1939) - 14; Svastis (1940) -13.

Since bone marrow biopsy studies were not described in connexion with any of these cases it follows that there is no proof that the anaemias were necessarily megaloblastic. Moreover, some of the descriptions of the peripheral blood were inadequate in that they failed to present unequivocal evidence of a genuine macrocytosis, or that the other features of a 'pernicious anaemia-like' blood picture were present.

The results of gastric analysis were stated in respect of seven of the cases and a histamine-fast achlorbydria was found in only four of these. Disease of the alimentary tract was present in three cases (coeliac disease, tuberculosis, megacolon); evidence of pyrexial infection was reported in two further cases and of endocrine dysfunction in another.

A haematopoietic response to parenteral liver therapy occurred in seven of the nine cases in which this treatment was tried. One of these patients remained in good health after liver treatment was stopped. One of the patients who failed to respond to liver therapy made a sustained recovery after a blood transfusion.

It will be apparent from this synopsis that a not inconsiderable proportion of the cases present features that invalidate a diagnosis of classical pernicious anaemia, whilst in others the available evidence does not necessarily render this diagnosis proven. Nevertheless, it may safely be accepted that in a number of the cases the anaemia was hyperchromic and macrocytic, responded to liver therapy, and was therefore presumably megaloblastic. 


\section{Case reports}

Methods. In each of the cases to be reported the examination of the peripheral blood followed conventional lines. The haemoglobin determinations were by the Haldane method (100 per cent. $=$ $13.8 \mathrm{gm}$. Hb.). Price-Jones' curves were not constructed, the extent of macrocytosis being assessed by careful inspection. Sternal marrow films were made by the squash method (Davidson, Davis and Innes, 1943) and stained by the May-Grünwald technique.

The liver extracts used in the treatment of the patients were from batches of known potency in cases of Addisonian pernicious anaemia. The proteolysed liver administered orally in cases 2 and 3 was the whole liver preparation described in a previous publication (Davis et al. 1943).

Case 1. D. M., a girl aged thirteen years, was first admitted to hospital on May 27, 1941, with a complaint of weakness, diarrhoea and pains in the limbs of a month's duration.

Interrogation of her mother, who was an. intelligent woman of the superior working class, elicited the information that the child had been small and immature for her age, but she had always been active and apparently healthy until a few months previously when gradually increasing pallor was first noticed. No history could be obtained of any previous alimentary abnormalities. The child's appetite seemed always to have been good, and the diet satisfactory. She had never previously suffered from vomiting or diarrhoea. The passage of abnormal stools had never been noted.

Physical eXAmination revealed a pale undernourished girl weighing only $56 \mathrm{lb}$. No enlargement of the spleen, liver and lymph glands was detected. The skin was dry and scaly but the tongue moist and clean with a normal surface. No signs of jaundice or purpura were seen.

LABORATORY INVESTIGATIONS. Gastric analysis showed no free acid in the resting juice, but 10 units of $\mathrm{HCl}$ were recorded after the injection of $0.5 \mathrm{mgm}$. histamine. The haemoglobin was 20 per cent.; red cell count, 860,000 per c.mm.; colour index, $1 \cdot 16$; reticulocytes, less than 1 per cent.; white cells, 1,400 per c.mm. The red cells displayed anisocytosis and macrocytosis. The white cells showed a granulopenia, no primitive cells being seen.

Sternal puncture revealed a megaloblastic marrow picture with a relative granulocyte maturation arrest at the myelocyte stage, the picture being similar to that seen in pernicious anaemia in the relapse phase (see fig. 1 and 2).

Progress. Ferrous sulphate was given by mouth and injections of anahaemin 4 c.c. twice weekly. Four days after the first injection a reticulocyte count of 10 per cent. was recorded, and this was followed by a progressive rise in haemoglobin, red cells and white cells, the patient being discharged on July 9, 1941, six weeks after admission, with a blood count of: haemoglobin, 75 per cent.; red cells, 3,650,000 per c.mm.; colour index, 1.03 , and white cells, 4,600 per c.mm. Her general condition was now much improved, and all symptoms had completely disappeared.

After the patient's discharge from hospital injections of anahaemin, 2 c.c., were continued fortnightly, but the blood condition showed no further improvement.

SECOND PERIOD IN HOSPITAL. She was readmitted to hospital on Jan. 3, 1942, with a haemoglobin reading of 65 per cent., red count of $2,650,000$ per c.mm., and a colour index of $1 \cdot 23$. The mean cell volume determined on this occasion was 140 c. $\mu$. A sternal puncture was performed, and the marrow picture was again found to be megaloblastic. Free $\mathrm{HCl}$ was found in the resting gastric juice.

The stools were normal, no steatorrhoea or diarrhoea being noted. She remained in hospital on this occasion for only twelve days during which she received a total of 24 c.c. pernaemon with no reticulocyte response or significant improvement in the red cell count.

On her return home the patient received pernaemon 4 c.c. weekly and subsequently her blood

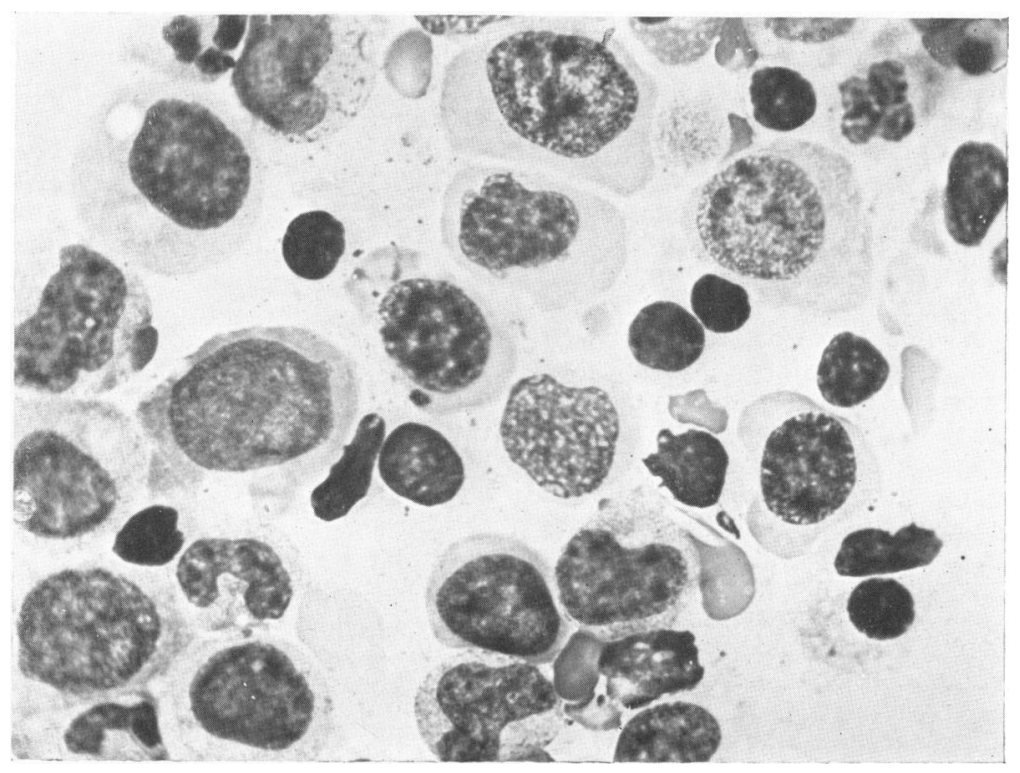




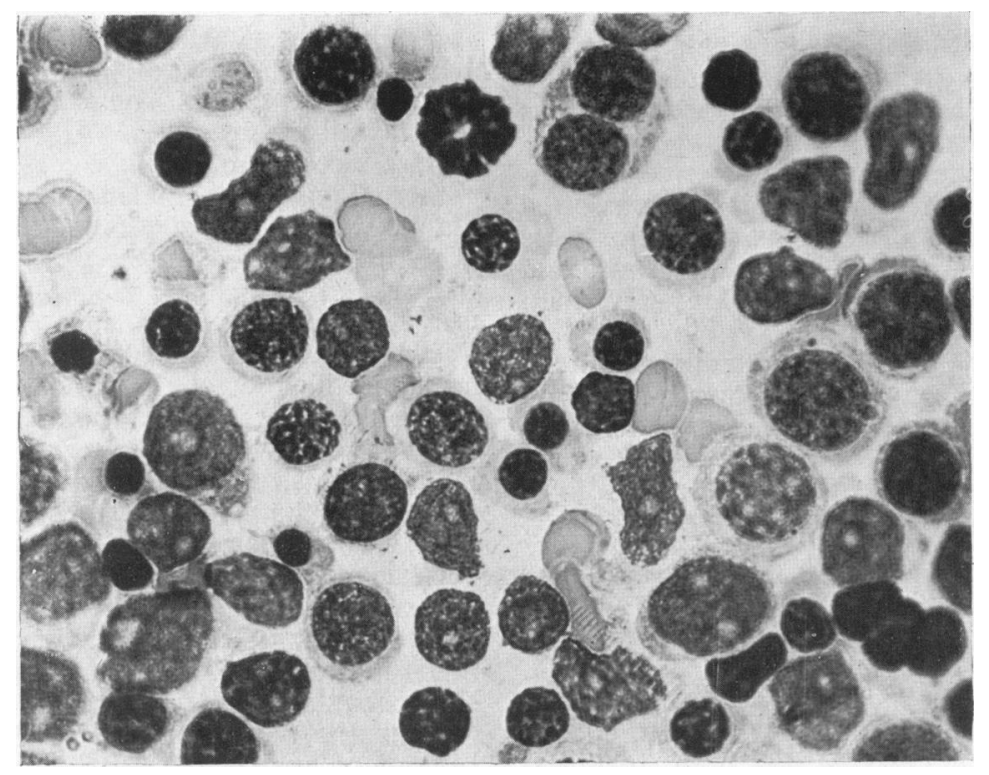

FIG. 2.-Microphotograph of sternal marrow film from a case of iron deficiency anaemia showing normoblastic erythropoiesis. Compare with figure $1 . \times 800$.

picture showed a slow but progressive improvement. After a few months the treatment was changed to anahaemin 2 c.c. weekly supplemented with iron and ascorbic acid. On Oct. 25, 1943, the blood count was: haemoglobin, 94 per cent.; red cells, $4,620,000$ per c.mm.; colour index, 1.02 ; mean cell volume, 92 c. $\mu$.; white cells, 5,200 per c.mm. The child appeared to be in good health but was still underweight. During the next few months, however, the patient complained of increasing fatigue on exertion and became paler, although she continued to receive anahaemin 2 c.c. weekly and ascorbic acid 150 mgm. daily.

THIRD PERIOD IN HOSPITAL. The patient was again admitted to hospital on March 3, 1944. She was now sixteen years of age, but her physical development was that of a girl several years younger. Her height was $57 \frac{1}{2}$ in. but her weight was only $72 \mathrm{lb}$. Secondary sexual characters were undeveloped, and menstruation had not started.

Several carious teeth were noted, and the tongue was smooth but not completely denuded. Apart from a few patches of impetigo on the face, the skin displayed no obvious abnormal features. The abdomen was somewhat full, but no enlargement of liver, spleen or other viscera was detected, nor were any lymph glands found to be enlarged. The bowel movements were normal, and it should be noted that at no time during the past two years had there been any symptoms of gastro-intestinal disorder.

Radiological investigation of the skeleton showed widespread decalcification and changes at the metaphyses similar to those seen in rickets. The sella turcica was normal in shape and size.

LABORATORY FINDINGS. Haemoglobin, 56. per cent.; red cells, $2,410,000$ per c.mm.; colour index, 1.16; mean cell volume, 107.9 c. $\mu$. ; reticulocytes, less than 1 per cent.; white cells, 5,600 per c.mm. The film showed a macrocytic blood picture.

Gastric analysis now revealed a histamine-fast achlorhydria. Stool analysis showed a total fat content of 26 per cent., of which 80 per cent. was split.

Serum calcium, 7.3 mgm. per cent.; plasma phosphorus, $4.6 \mathrm{mgm}$. per cent.; and plasma phosphatase, 95 units (modified Kay); icteric index, 4.

Progress. One injection of anahaemin 4 c.c. resulted in a reticulocyte response of 5 per cent. and a subsequent rise in haemoglobin to 70 per cent., and of red cells to $3,480,000$ per c.mm. at the end of a fortnight. Treatment was then continued with weekly injections of anahaemin and vitamin D, ascorbic acid, iron, calcium lactate, and ol. phosphorat. by mouth daily.

By April 26, 1944, nearly two months after readmission to hospital; her weight had increased by $5 \mathrm{lb}$., and the haemoglobin had risen to 84 per cent. with 4,510,000 red cells per c.mm. On this day, however, she suffered a green-stick fracture of the left femur.

Comment. From the haematological aspect, the significant features of this case are the development of a severe megaloblastic anaemia at a time when free hydrochloric acid was present in the patient's gastric juice, and the tendency to relapse on maintenance treatment with high dosage of parenteral liver extracts. The response of the patient to this form of therapy is difficult to explain, particularly with regard to the months immediately preceding her last admission to hospital when her blood condition showed progressive deterioration. Further questioning of mother and doctor provided confirmation that at this time she received regular injections of anahaemin. There is no reason to doubt the potency of this material since it was from the same batches, and obtained from the same source as that supplied to the hospital. The prompt haematopoietic response to a single injection of 4 c.c. of anahaemin given immediately after her re-admission 
to hospital is accordingly puzzling. The only factors of possible therapeutic significance that can be attributed to hospitalization were the rest in bed and possibly a more nutritious diet.

The defective haematopoiesis would appear to have its origin in some nutritional disorder rather than in inadequate production of intrinsic factor, for the delayed somatic development and the generalized skeletal de-calcification point to an abnormality in absorption or metabolism. The nature of such an abnormality is obscure however. In view of the child's appetite and dietetic history it would not appear to be attributable to an inadequate intake. The absence of history of vomiting, diarrhoea or steatorrhoea renders a retrospective diagnosis of coeliac disease questionable.

It is significant, however, that during the last admission to hospital a histamine-fast achlorhydria was demonstrable for the first time, for the development of achylia in a patient of this age is of course quite abnormal and indicative of a pathological condition of the alimentary tract. In view of this finding it may be argued that the case is one of Addisonian pernicious anaemia, but the fact that the achylia did not develop until two years after the onset of the severe megaloblastic anaemia, together with the other evidences of defective nutrition, makes such a diagnosis difficult to accept.

The possibility of a pituitary insufficiency was considered, since the association of this condition with achlorhydria and severe anaemia which may be macrocytic, has been described by Snapper, Groen, Hunter and Witts (1937). In the present case, although no definite evidence in support of such a conception has so far been provided, the possibility of endocrine dysfunction should obviously not lightly be discarded.

Case 2. J. B., a boy aged fourteen years, was admitted to hospital on May 7, 1942, complaining of slight diarrhoea of nine months' duration and a recent loss of one stone in weight. No evidence could be elicited suggestive of a defective diet or of any previous alimentary disorder. The previous personal and family medical history was not significant.

Examination revealed a pale, undernourished child with a red, smooth tongue, but no other abnormalities were detected. His height was 54 in. and weight $54 \mathrm{lb}$

Examination of the blood showed a severe hypochromic microcytic anaemia, the count being: haemoglobin, 17 per cent.; red cells, $1,050,000$ per c.mm.; colour index, 0.81 ; reticulocytes, 3 per cent.; white cells, 4,500 per c.mm.; platelets, 320,000 per c.mm. Red cell fragility was normal and no urobilinuria or other evidence of disordered bile pigment metabolism was noted.

Stool analysis showed 11.2 per cent. total fats, of which 55.8 per cent. were split. Radiological examination of chest and abdomen was negative. A tuberculin test gave a mild positive reaction.

Progress. A blood transfusion was given and iron and ascorbic acid administered. Thereafter a rapid improvement in the patient's general and haematological condition occurred, but two weeks after admission to hospital a transient ascites appeared which lasted for ten days. After its disappearance a firm enlargement of the liver was noted, the lower edge of which extended 1 in. below the costal margin. This enlargement persisted. The patient was discharged from hospital with a red cell count of $5,290,000$ per c.mm. with 96 per cent. haemoglobin in excellent health and weighing $74 \mathrm{lb}$. He remained well for some months, but then again began to lose weight and energy.

SECOND PERIOD IN HOSPITAL. He was re-admitted to hospital on May 25, 1943. Physical examination now showed a protuberant abdomen with the same degree of hepatic enlargement as previously noted. The spleen was not palpable, but apart from manifestations of anaemia no other clinical abnormalities were noted. His weight, however, was only $64 \mathrm{lb}$. with a height of $54 \frac{1}{2}$ inches.

LABORATORY FINDINGS. Blood examination now showed a macrocytic anaemia: haemoglobin, 44 per cent.; red cells, 1,800,000 per c.mm.; colour index, $1 \cdot 22$; reticulocytes, less than 1 per cent.; white cells, 3,300 per c.mm. The red cells displayed marked anisocytosis with many oval-shaped macrocytes, the picture being characteristic of pernicious anaemia. Sternal puncture revealed a typical megaloblastic picture. Icteric index, 13; blood cholesterol, $160 \mathrm{mgm}$. per cent.; Wassermann reaction, negative; gastric analysis, histamine-fast achlorhydria; stools contained no occult blood; fat analysis - total fats, 27 per cent. of which 33 per cent. were split.

Progress. An injection of anahaemin 4 c.c. resulted in no haematopoietic response in ten days. Proteolysed liver was then given orally, $\frac{1}{2} \mathrm{oz}$. daily; no iron or other haematinics being administered. This was followed by a reticulocyte response of 9 per cent. on the tenth day and a rapid and progressive rise in the red cell and white cell counts. Reticulocyte counts were unfortunately not recorded throughout the first ten days of the proteolysed liver therapy, consequently it is probable that the maximum reticulocyte rise was higher than the figure noted above. The patient was discharged on July 17,1943 , with a red cell count of $4,500,000$ per c.mm.; haemoglobin, 84 per cent.; colour index, 0.93 ; white cells, 5,400 per c.mm. and a gain in weight of $9 \mathrm{lb}$.

Subsequent to the patient's discharge from hospital the oral liver therapy was replaced by parenteral injections of a crude liver extract (plexan) 2 c.c. twice monthly. When seen five months later he was in excellent condition and the blood count was within normal limits, but the liver was still enlarged. On March 8, 1944, however, eight months after leaving hospital, the patient still felt quite well, but his blood condition had deteriorated to: haemoglobin, 80 per cent.; red cells, 3,820,000 per c.mm. Further injections of liver extract were now stopped and replaced by proteolysed liver, $\frac{1}{4} \mathrm{oz}$. daily given by mouth. A month later the haemoglobin had risen to 94 per cent. and the red count to $4,380,000$ per c.mm. The white cell count was 8,600 per c.mm. The patient was in excellent health and there was now no evidence of hepatic enlargement. All treatment was now discontinued. Two months later, on June 14, 1944, the boy was still in excellent health, his haemoglobin being 90 per cent. with 4,440,000 red cells per c.mm. and white cells 5,400 per c.mm. 
Comment. An interesting feature of this case is the onset of the severe hyperchromic macrocytic anaemia a year after the hypochromic microcytic anaemia.

Examples of anaemias changing from hypochromic to hyperchromic have been described in adults by Davidson and Fullerton (1938) and Miller and Dameshek (1941). The rarity of the phenomenon is emphasized by the first-mentioned authors who state that in a study of a thousand cases of hypochromic anaemia only three were known to develop a macrocytic anaemia subsequently.

Miller and Dameshek suggest that the transformation may result from a progressive disorder of the gastric mucosa leading first to achlorhydria and inadequate iron absorption and later to interference with production of intrinsic factor and consequent development of pernicious anaemia.

In the present case it is unfortunate that no gastric analysis was done during the stage of hypochromic anaemia, but it will have been noted that achylia was present after the onset of the hyperchromic stage. In spite of this it is thought that the under-developed physique of the boy which is highly suggestive of a generalized nutritional or metabolic abnormality, and the inadequate response to fractionated liver extracts, justify the rejection of a diagnosis of Addisonian pernicious anaemia.

As in the previous case, no definite etiological factor can be incriminated. In view of the development of ascites during the first admission to hospital, a diagnosis of abdominal tuberculosis was considered, since it was thought that a tuberculous involvement of the lacteals might have resulted in defective absorption and consequent anaemia. The subsequent course of the patient, however, provided no confirmatory evidence for such a diagnosis, although it does not necessarily warrant its final rejection.

The long-continued hepatic enlargement noted in this case makes it tempting to attempt to correlate this finding with the pathogenesis of the anaemia. It is conceivable that in the first place defective assimilation may have resulted not only in an iron deficiency leading to the hypochromic anaemia, but in a deficiency of methionine or other factors necessary for normal functioning of the liver, thus giving rise to disease of this organ. The persistence of such a pathological condition after the correction of the hypochromic anaemia by adequate iron therapy, provides a plausible explanation for the subsequent development of the macrocytic (megaloblastic) anaemia. The response of the macrocytic anaemia to proteolysed liver therapy and the eventual regression of the hepatomegaly may be explained not only by haematopoietic virtue of proteolysed liver, but by its high content of aminoacids including methionine (1 per cent.) which would presumably be of peculiar value in correcting a state of hepatic dysfunction. It will be appreciated that the foregoing suggestion is purely hypothetical, and furthermore does not attempt to explain the nature of the underlying faulty assimilation.
An observation of considerable therapeutic interest was the failure to maintain satisfactory haematopoiesis with injections of plexan, and the subsequent success of proteolysed liver orally after the patient's final discharge from hospital. Reference has already been made to data to be published elsewhere demonstrating the successful treatment with proteolysed liver of cases of megaloblastic anaemia shown to be refractory to treatment with anahaemin. The behaviour of the present case during the patient's second period in hospital provides further evidence on this point. Anahaemin, however, is a refined, and highly purified fractionated liver extract, whereas plexan is stated to be a crude extract containing factors of possible haematinic value not present in the more highly refined extracts. So far as I am aware no trial has previously been reported in which the comparative merits of such a crude liver extract and of proteolysed liver have been assessed in the treatment of a refractory anaemia.

Case 3. This case has been included by Davis and Davidson (1944) along with other examples of megaloblastic anaemias refractory to treatment with parenteral liver extracts but responsive to proteolysed liver therapy. As an example of megaloblastic anaemia in childhood, however, it is considered that a brief account of the case merits inclusion in the present paper.

The patient, J. R., was a girl aged twelve years admitted to hospital on August 12, 1943, on account of progressive loss of weight and energy and of increasing pallor. These symptoms had been noticed only during the preceding two months. Formerly, she had always been a healthy, energetic child, and there was no history suggestive of coeliac disease or other alimentary disorder. Her social circumstances were comfortable and provided no grounds for suspecting inadequacy of diet.

On examination the girl was found to be very pale and listless. Her weight was $70 \mathrm{lb}$. No signs of purpura or of jaundice were evident, although the gums were spongy and bled easily. The tongue was clean, moist and not smooth. The liver was firm, and its lower edge was palpable one inch below the costal margin. No enlargement of the spleen or lymph glands was detected, nor were any other clinical abnormalities noted. The stools appeared to be normal, and there was no diarrhoea. Radiological examination of the chest was negative, but confirmed the hepatic enlargement.

LABORATORY FINDINGS. Examination of the blood revealed a macrocytic anaemia with pronounced anisocytosis and poikilocytosis with numerous large macrocytes. The red cell count was $1,130,000$ per c.mm.; haemoglobin, 32 per cent.; colour index, 1.42 ; reticulocytes less than 1 per cent.; white cells, 4,600 per c.mm. Platelets were not counted, but were scanty in cover-slip films. Sternal puncture showed a typical megaloblastic marrow picture. The Wassermann reaction was negative. The gastric juice contained free hydrochloric acid. The icteric index was 13; no excess of urobilinogen was present in the urine. The stools were repeatedly examined for occult blood with negative results, and a fat analysis showed $13 \cdot 5$ per cent. total fat of which 71.4 per cent. was split.

Progress. An injection of anahaemin, 4 c.c., 
was given and repeated after six days with no evidence of any haematopoietic response. Five days after the second injection the haemoglobin fell to 30 per cent. and the patient developed a retinal haemorrhage. A blood transfusion of one pint was given which raised the haemoglobin to 44 per cent. and was followed by two more injections of anahaemin (4 c.c.) without response; the haemoglobin falling to 32 per cent. four days after the last injection.

The patient was then put on proteolysed liver by mouth, working up to $1 \frac{1}{2} \mathrm{oz}$. daily. This was followed by a reticulocyte count of 28 per cent. on the fifth day after the start of this form of therapy and a progressive clinical and haematological improvement. On Sept. 28, 1943, twenty-seven days after beginning the proteolysed liver, the red cell count was $4,500,000$ per c.mm.; the haemoglobin 85 per cent.; colour index, 0.94 and the white cell count 6,000 per c.mm. The patient's general condition was now considerably improved and she had gained $10 \mathrm{lb}$. in weight since admission to hospital. She was accordingly discharged home and did not receive any further liver or any other haematinic treatment.

When seen on Oct. 26, 1943, she was feeling very well and her blood picture was normal, the red cell count being 4,500,000 per c.mm. with haemoglobin 90 per cent. The lower edge of the liver was just palpable and was neither firm nor tender. Two months later her haemoglobin was 100 per cent. with $4,900,000$ red cells per c.mm. and her general health was excellent, and has remained so during recent months.

Comment. The presence of free hydrochloric acid in the gastric juice; the failure of response to injections of liver extract, the recovery on proteolysed liver and subsequent maintenance of health without further treatment are all considered to be features which invalidate a diagnosis of Addisonian pernicious anaemia.

No satisfactory explanation can be advanced for the apparently temporary failure in haematopoietic function displayed by this patient. The rapid loss of weight which accompanied the development of the symptoms of anaemia is suggestive of a temporary failure in absorption from the alimentary tract, but the absence of vomiting, diarrhoea or steatorrhoea renders this explanation purely conjectural. The slight degree of hepatic enlargement cannot with conviction be considered evidence of a primary disease of the liver, since such minor degrees of hepatomegaly are commonly found as secondary manifestations in many forms of anaemia, but on the other hand it is of course open to a hypothetical explanation similar to that considered in 'connexion with case 2 .

In the meantime the child will need to be kept under observation since only time will tell whether the failure in haematopoiesis was a temporary incident or whether it was the prelude to a permanent disorder.

\section{Discussion}

No further detailed discussion of the cases described in this paper is called for since their salient clinical and haematological features have already been considered. Certain generalizations may, however, be drawn from a consideration of the three cases in relation to the questions of diagnosis, pathogenesis and treatment.

Based solely on the haematological findings and the morphology of the sternal marrow films, a diagnosis of pernicious anaemia would have been warranted in all three cases, but in each case consideration of various clinical features renders such a diagnosis untenable or, at least, improbable. The pathogenesis in each case was obscure. In cases 1 and 2, circumstantial evidence points to longstanding nutritional dysfunction, but there is no adequate evidence for the diagnosis of any pathological or clinical entity of likely etiological significance. The etiology of the case 3 is still more obscure, since in this case, the failure in haematopoiesis seems to have been of a temporary nature.

The response to treatment was unusual in all cases. In case 1, maintenance of haematopoiesis at anything approaching an adequate level called for injections of liver extract in a dosage considerably exceeding that required in straightforward cases of pernicious anaemia. The other two cases were shown to be completely unresponsive to parenteral liver therapy but readily amenable to proteolysed liver given by mouth.

Reference has already been made to a communication to be published elsewhere (Davis and Davidson, 1944) dealing with the successful treatment with proteolysed liver of cases of megaloblastic anaemia which had proved refractory to injections of fractionated liver extracts. The significance of these observations is discussed in the paper referred to and will accordingly not be considered further here. It may be noted, however, that it is suggested that the arrested megaloblastic maturation in these refractory anaemias results from a deficiency of some additional haematopoietic factor, present in proteolysed liver but absent, or present only in inadequate quantity, in fractionated liver extracts. The possible effect of proteolysed liver therapy on hepatic dysfunction associated with anaemia has already been referred to in connexion with case 2 .

\section{Summary and conclusions}

1. The term megaloblastic anaemia is defined, and its pathogenesis is discussed.

2. Previous reports of macrocytic anaemias in childhood are reviewed, and attention is drawn to the rarity of the condition and to the inadequacy of the data for the justification of a diagnosis of Addisonian pernicious anaemia in most of the cases.

3. Three cases of megaloblastic anaemia are described in children aged twelve, thirteen and fifteen years. The pathogenesis of these cases is considered.

Although the blood and sternal marrow pictures were typical of pernicious anaemia, arguments are advanced against the acceptance of this diagnosis in the present cases, in all of which it is believed that defective assimilation from the alimentary tract may 
have been an etiological factor of paramount importance.

Two of the cases proved refractory to parenteral injections of liver extracts of known potency but responded promptly to proteolysed liver administered orally.

In one case the macrocytic, hyperchromic anaemia was preceded a year earlier by a severe hypochromic anaemia.

\section{Acknowledgements}

Thanks are due to Professor L. S. P. Davidson for helpful advice and criticism, to Professors W. T. Ritchie, O.B.E., and D. M. Dunlop and to Dr. W. D. D. Small, C.B.E., for their kindness in granting facilities for studying patients under their care, and to Dr. D. Riding of Messrs. Evans, Lescher and Webb for supplies of proteolysed liver.

\section{REFERENCES}

Adams, J. M., and McQuarrie, J. (1938). J. Pediat., 12, 176.

Bachman, A. L. (1936). Amer. J. Dis. Child., 52, 633.

Barbé, P. (1939). Bull. Soc. Pédiat. Paris, 37, 47.

Carr, J. G. (1920). Amer. J. med. Sci., 160, 737.

Castle, W. B. (1928). Proc. roy. Soc. Med., 22, 1214.

Cole, L. (1941). Lancet, 2, 759.

Davidson, L. S. P., Davis, L. J., and Innes, J. (1942). Brit. med. J., 2, 31 .

,, (1943). Edinb. med. J., 50, 226. 43.
Davidson, L. S. P., and Gulland, G. L. (1930) Pernicious anaemia, Lond.

Davis, L. J., Davidson, L. S. P., Riding, D., and Shaw, G. E. (1943). Brit. med. J., 1, 655.

,-- (1944). Quart. J. Med. In press.

Eckman, P. F., and Rowe, O. W. (1929). Minnesota Med., 12, 788.

Faber, H. K. (1928). Amer. J. Dis. Child., 36, 1121.

Fanconi, G. (1927). Jb. Kinderheilk., 117, 257.

Fouts, P. J., and Garber, E. (1942). Amer. J. Dis. Child., $64,270$.

Fullerton, H. W. (1943), Brit. med. J., 1, 158.

Israëls, M. C. G., and Wilkinson, J. F. (1940). Quart. J. Med., 9, 163.

Kersley, G. D. (1935). Brit. med. J., 2, 994.

Kusonoki, M. (1914). Korresp Bl. schweiz. Arz., 44, 833.

Langmead, F. S., and Doniach, I. (1937). Lancet, 1, 1048.

Magnusson, J. H., and Hamne, B. (1939). Acta. paediat. Stockh., 25, 189.

Miller, E. B., and Dameshek, W. (1941). Arch. intern. Med., 68, 375.

Mödlinger, P. (1937). Orv. Hetil., 81, 247.

Montgomery, E. W. (1926). Canad. med. Ass. J., 16, 244.

Murphy, W. P. (1939). Anemia in practice, Phila.

Panton, P. M., Maitland-Jones, A. G., and Riddoch, G. (1923). Lancet, 1, 274.

Parsons, L. G., and Hawksley, J. C. (1933). Arch. Dis. Childh., 8, 117.

Snapper, I., Groen, J., Hunter, D., and Witts, L. J. (1937). Quart. J. Med., 6, 195.

Svastis, P. (1940). Orv. Hetil., 84, 179.

Templeton, W. L. (1939). Lancet, 2, 1221.

Trowell, H. C. (1943). Trans. roy. Soc. Trop. Med. Hyg., 37, 19.

Veeneklass, G. M. H. (1940). Ned. Tijdschr. Geneesk., $84,3860,4517$.

Vischer, D. (1923). Schweiz. med. Wschr., 4, 1104.

Wilson, C. R., and Evans, F. A. (1924). Johns Hopk. Hosp. Bull., 35, 38. 